\title{
Developing ultrafine-grained materials with high strength and good ductility for micro-forming applications
}

\author{
Yi Huang ${ }^{1, a}$, Jie $\mathrm{Xu}^{2,3}$, and Terence G. Langdon ${ }^{1,4}$ \\ ${ }^{1}$ Materials Research Group, Faculty of Engineering and the Environment, University of Southampton, \\ Southampton SO17 1BJ, UK \\ ${ }^{2}$ Key Laboratory of Micro-systems and Micro-structures Manufacturing, Ministry of Education, \\ Harbin Institute of Technology, Harbin 150080, China \\ ${ }^{3}$ School of Materials Science and Engineering, Harbin Institute of Technology, Harbin 150001, China \\ ${ }^{4}$ Departments of Aerospace \& Mechanical Engineering and Materials Science, \\ University of Southern California, Los Angeles, CA 90089-1453, USA
}

\begin{abstract}
Materials with ultrafine grain sizes are attractive for use in micro-forming operations. High-pressure torsion (HPT) is an effective technique that allows disc materials subjected to torsional deformation to generate microstructures with significant grain refinement. Generally, ultrafine-grained materials exhibit high strength but their ductility is limited because they have both a low rate of strain hardening and a low strain rate sensitivity. A special processing route by utilizing HPT and short term annealing at different temperatures was developed to obtain balanced high strength and good ductility in an ultrafine-grained $\mathrm{Al}-1 \% \mathrm{Mg}$ alloy which will increase the production rate and quality in micro-forming.
\end{abstract}

\section{Introduction}

Non-silicon material-based micro-manufacturing is an emerging field that has attracted considerable research interest [1]. As demands on miniature/micro-metal products increase significantly, micrometal-forming becomes an attractive option in the manufacturing of these products due to its advantageous characteristics for mass production with controlled quality and low cost [2]. The microforming, in the context of metal forming, is understood to be the production of parts or structures with at least two dimensions in the submillimetre range [3, 4]. However, challenges arise when the sizes/features are reduced to tens or hundreds of microns, or the precision requirements for macro/miniature parts are reduced to less than a few microns [2]. As a result, the ratio between the dimensions of a part and microstructural parameters changes with miniaturization [4]. This leads to so-called size effects which prevent the application of conventional forming processes in the field of micro-forming. The grain size is believed to be a limiting factor for the minimum size of geometrical features that can be produced

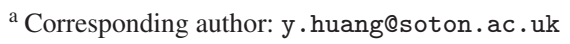

This is an Open Access article distributed under the terms of the Creative Commons Attribution License 4.0, which permits unrestricted use, distribution, and reproduction in any medium, provided the original work is properly cited. 


\section{MATEC Web of Conferences}

by micro-forming [4-6]. Therefore, developing ultrafine-grained (UFG) materials or nanostructured materials with high strength and good ductility will be an important requirement for micro-forming applications.

In practice, the total deformation achieved by conventional thermo-mechanical processing is severely limited by the reduction in the cross-sectional areas of the samples. As a result, this type of processing is usually not sufficient to promote a homogeneous refinement of the initial coarse structure of the material. Equal-channel angular pressing (ECAP) and high-pressure torsion (HPT) are most efficient severe plastic deformation (SPD) techniques that may be used to produce highstrength ultrafine-grained and nanostructured materials [7-9]. The sample sizes are not changed during ECAP or HPT processing, therefore theoretically the materials may be subjected to many passes of ECAP processing or many turns of HPT processing to achieve significant grain refinement and strength improvement. The ECAP process is not continuous while HPT permits obtaining extremely large strains in a single operation. Processing by HPT is especially attractive because it leads to grains which are generally smaller than those produced using ECAP [9]. After SPD processing, it was established that UFG metals have highly deformed microstructures with high dislocation densities within the grains [10] and with high-energy non-equilibrium grain boundaries containing an excess of extrinsic dislocations [11, 12]. Generally, UFG metals exhibit high strength but their ductility is limited because they have both a low rate of strain hardening and a low strain rate sensitivity $[13,14]$. This limited ductility in SPD-processed UFG materials may cause failure during micro-forming.

There is only limited research on the application of SPD processed materials in micro-forming [6, 15-18]. Therefore, experiments were conducted to investigate HPT processing of an Al-1\% Mg alloy and to develop a processing route to improve the material ductility after SPD processing in order to attain a material suitable for micro-forming applications.

\section{Experimental material and procedures}

An $\mathrm{Al}-1 \% \mathrm{Mg}$ alloy was received in the form of extruded rods having diameters of $13 \mathrm{~mm}$ : further details are given in an earlier report [19]. Before machining, the as-received material was annealed at $773 \mathrm{~K}$ for $1 \mathrm{~h}$ and the average grain size after annealing was $\sim 400 \mu \mathrm{m}$. After annealing, the material was first machined to reduce the diameter to $9.85 \mathrm{~mm}$, then it was sliced into discs with thicknesses of $\sim 1.2 \mathrm{~mm}$. The sliced discs were ground with abrasive papers to final thicknesses of $\sim 0.8 \mathrm{~mm}$ to make them ready for HPT processing.

The discs were processed by HPT under quasi-constrained conditions [20] through total numbers of turns, $\mathrm{N}$, of 1,5 and 10 at room temperature using an imposed pressure of $6.0 \mathrm{GPa}$ and a rotational speed for the lower anvil of $1 \mathrm{rpm}$. Following HPT, 10 turn samples were selected for low temperature annealing at $373,423,473$ and $523 \mathrm{~K}$ for 10 minutes in a vacuum environment.

The HPT-processed discs and post-HPT annealed discs were mounted in cold resin and carefully ground with abrasive paper. The samples were polished with diamond paste, a final polishing was performed using a colloidal silica solution and then the distorted surface layer (several microns thick) was removed by Ar ion milling. The grain structure in the HPT-processed and the post-HPT annealed specimens was studied at the edge of the disc by electron back-scattered diffraction (EBSD) using a FEI Quanta 3D scanning electron microscope. For the initial $773 \mathrm{~K}$ annealing sample, the microstructure was examined using a JSM6500F thermal field emission scanning electron microscope (SEM) coupled with EBSD.

The Vickers microhardness, Hv, was measured on polished mirror-like disc surfaces using a FM300 microhardness tester equipped with a Vickers indenter. The hardness measurements used a load of $100 \mathrm{gf}$ and dwell times of $15 \mathrm{~s}$. These measurements were taken at positions along the disc diameter separated by incremental distances of $0.3 \mathrm{~mm}$ with four individual points recorded around each selected position separated from this position by distances of $0.15 \mathrm{~mm}$. These measurements were used to provide the 

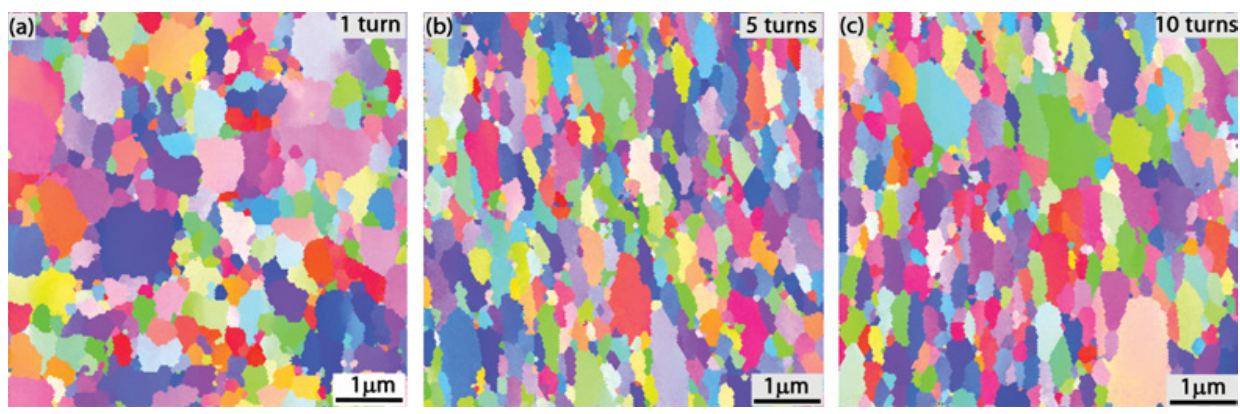

Figure 1. Microstructures after HPT processing through (a) 1, (b) 5 and (c) 10 turns.

variations of hardness across each disc together with the associated error bars recorded at the 95\% level.

Tensile specimens were cut from unprocessed samples, 10 turns HPT processed samples, and samples subjected to 10 turns HPT processing plus post-HPT annealing at 423, 473 and $523 \mathrm{~K}$. In order to avoid any microstructural inhomogeneities in the centres of the discs, two tensile specimens were prepared from each disc using electro-discharge machining with these specimens arranged symmetrically on either side of the disc centre [21]. The miniature tensile specimens had gauge lengths and widths of $1 \mathrm{~mm}$. Tensile testing was conducted on an Instron 5569 testing machine with strain rates of $1.0 \times 10^{-3}$ and $1.0 \times 10^{-2} \mathrm{~s}^{-1}$.

\section{Experimental results}

\subsection{The evolution of grain structure during HPT}

Figure 1 displays typical EBSD images taken from near the edges of discs for samples processed by HPT. The image in Fig. 1(a) represents the microstructure after 1 turn of HPT processing and it shows significant grain refinement compared to the unprocessed condition with the grain size reduced from $\sim 400 \mu \mathrm{m}$ for the unprocessed condition to $\sim 240 \mathrm{~nm}$. With further increasing $\mathrm{N}$ to 5 turns, the grains are further refined to $200 \mathrm{~nm}$ in Fig. 1(b). Figure 1(c) shows that after the number of turns is increased to 10 , some coarse grains appear in the microstructure and this leads to an average grain size increase to $230 \mathrm{~nm}$. The grain refinements in the early stage of HPT processing and the coarse grain appearance in the later stage of HPT processing are well demonstrated in Fig. 1.

The distributions of the grain boundary misorientations are shown in Fig. 2 where the angles $>15^{\circ}$ are designated high-angle boundaries. After 1 turn of HPT, there are a very large number of high-angle boundaries representing $80 \%$ of all boundaries in the sample. As the number of turns is increased to 5 turns, the number fraction of high-angle boundaries is $85 \%$. After 10 turns, the number fraction of high-angle boundaries is $80 \%$. These fractions are sufficiently similar that it is reasonable to conclude there is no significant change with increasing numbers of turns in HPT.

\subsection{The evolution of hardness during HPT}

The hardness evolution with different numbers of turns during HPT processing is shown in Fig. 3. After 1 turn, the disc centre has the lowest hardness value, then the hardness increases almost linearly from the centre to the edge and reaches a maximum at the disc edge. After 5 and 10 turns, from the disc centre to the edge the hardness values distribute uniformly along the diameter but the hardness level 


\section{MATEC Web of Conferences}

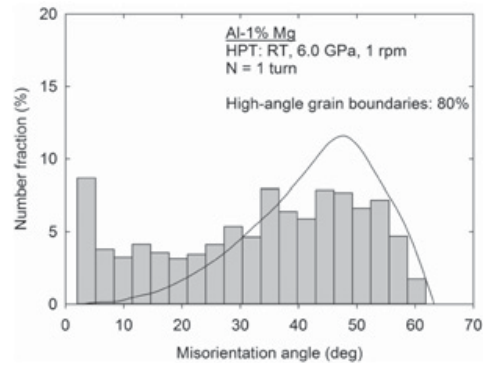

(a)

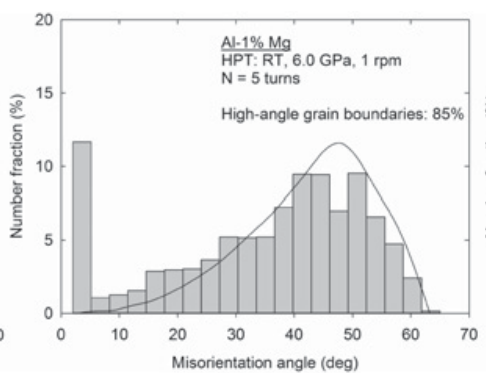

(b)

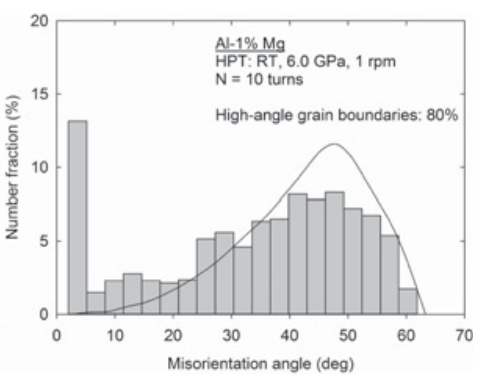

(c)

Figure 2. Misorientation distributions after HPT processing through (a) 1, (b) 5 and (c) 10 turns.

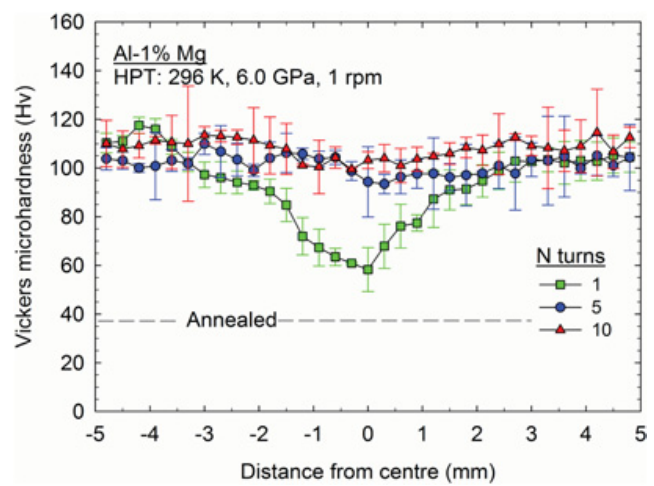

Figure 3. Distribution of Vickers microhardness, Hv, along the diameters of discs processed by HPT through 1, 5 and 10 turns.

at 10 turns is slightly above 5 turns. Figure 3 demonstrates that after 5 and 10 turns the discs have reasonable saturation hardness across the diameters.

\subsection{The evolution of microhardness and grain size during the post-HPT annealing}

The overall microhardness values and grain size variations following post-HPT annealing are summarized in Fig. 4. After $373 \mathrm{~K}$ annealing, the average grain size and the microhardness has similar values to the 10 turns sample at room temperature $(296 \mathrm{~K})$ as shown in Fig. 4. Further increasing the annealing temperature to 423,473 and $523 \mathrm{~K}$, the hardness values drop and this is accompanied by an increase in average grain size. The grain size increasing rate, which is temperature dependent, is smaller from $373 \mathrm{~K}$ to $423 \mathrm{~K}$ than from $423 \mathrm{~K}$ to $473 \mathrm{~K}$ and from $473 \mathrm{~K}$ to $523 \mathrm{~K}$. After annealing at 423 , the average grain size is $\sim 360 \mathrm{~nm}$.

\subsection{Tensile properties}

Figure 5 shows the material tensile properties with testing strain rates of $10^{-3}$ and $10^{-2} \mathrm{~s}^{-1}$. In the unprocessed condition (i.e. as-annealed at $773 \mathrm{~K}, 1 \mathrm{~h}$ ), the material has the highest elongation and the smallest stress for all two strain rates. As shown in Fig. 5, with strain rates of $10^{-3}$ and $10^{-2} \mathrm{~s}^{-1}$ the HPT-processed 10 turns sample has a significant strength improvement compared to the 


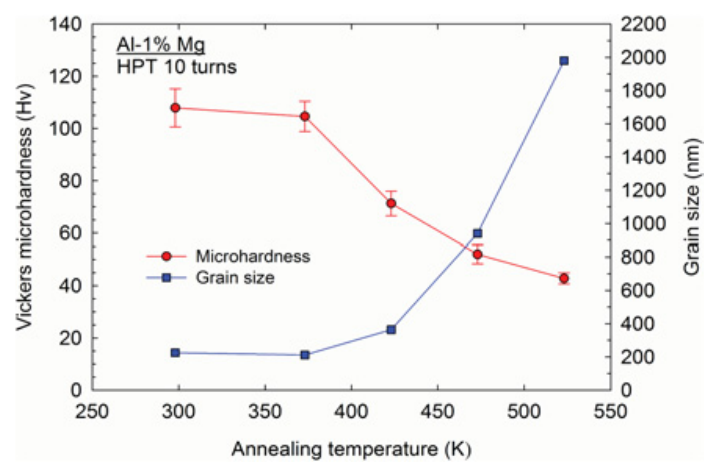

Figure 4. Variation of the microhardness and grain size with the post-HPT annealing temperature.

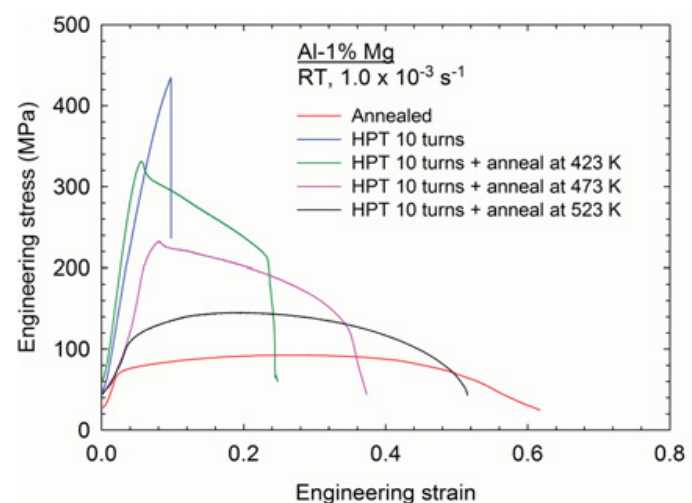

(a)

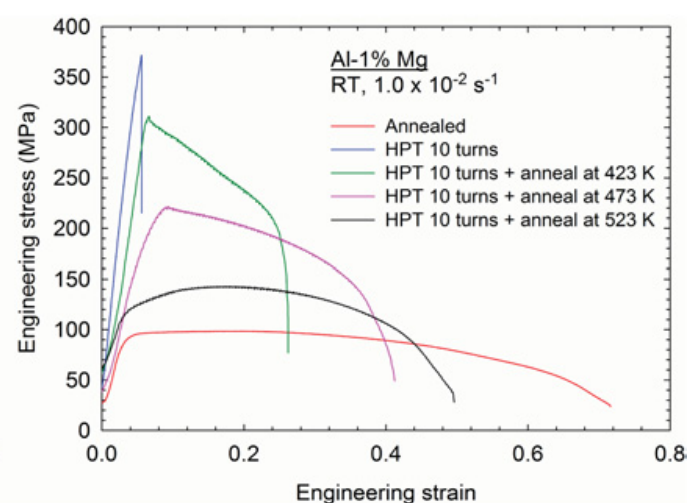

(b)

Figure 5. Stress-strain curves at room temperature for the annealed material, after HPT through 10 turns and after HPT through 10 turns and annealing at 423,473 and $523 \mathrm{~K}$ at (a) $1.0 \times 10^{-3}$ and $1.0 \times 10^{-2} \mathrm{~s}^{-1}$.

unprocessed condition with the material breaking before the yield point. Post-HPT annealing samples show decreasing strength and increasing elongation with increasing annealing temperatures. Only the sample subjected to $423 \mathrm{~K}$ post-HPT annealing exhibits a high stress level inherited from HPT processing and at the same time the elongation improves to a reasonable value compared to the lower elongation from the HPT-processed sample. Thus, it is concluded that the sample subjected to $423 \mathrm{~K}$ post-HPT annealing has balanced high strength and a reasonable elongation.

\section{Discussion}

Exceptional grain refinement was achieved in an $\mathrm{Al}-1 \% \mathrm{Mg}$ alloy having an initial grain size of $\sim 400 \mu \mathrm{m}$. Processing by HPT at room temperature led to an average grain size of $\sim 230 \mathrm{~nm}$ after 10 turns. Imposing a short term anneal of 10 minutes after the HPT processing has a significant effect on the microstructure and tensile properties of the HPT-processed specimens. There exists an optimum condition for the $\mathrm{Al}-1 \% \mathrm{Mg}$ alloy by processing using HPT at room temperature and then giving the material a short anneal for 10 minutes at $423 \mathrm{~K}$.

Pure aluminium processed by ECAP to 8 passes produced materials with an average grain size of $1.3 \mu \mathrm{m}$ and this has been successfully applied to micro-forming of micro-turbine parts $[17,18]$. It was 


\section{MATEC Web of Conferences}

reported that the geometries and surface quality of the compressed samples can be improved using UFG pure $\mathrm{Al}$ processed by ECAP through 8 passes by comparison with coarse-grained pure $\mathrm{Al}$ [18].

The widely accepted deformation mechanism in micro-forming of polycrystalline metallic alloys is grain boundary sliding and grain rotation in polycrystalline aggregates $[2,6,16]$. As such, the grain size is believed to be a limiting factor on the minimum size of the geometrical features that can be produced by micro-forming [15]. Obviously, HPT-processed Al-1\% $\mathrm{Mg}$ has much finer grain size $(\sim 230 \mathrm{~nm})$ than $\mathrm{Al}$ in ECAP processing $(\sim 1.3 \mu \mathrm{m})$. Even after post-HPT short term annealing at $423 \mathrm{~K}, \mathrm{Al}-1 \%$ $\mathrm{Mg}$ has a grain size as fine as $\sim 360 \mathrm{~nm}$, which remains much finer than in ECAP-processed pure Al. Therefore, HPT processing plus post-HPT annealing provides an alternative processing route for the development of materials suitable for use in micro-forming.

\section{Summary and conclusions}

[1] Experiments were conducted on an $\mathrm{Al}-1 \% \mathrm{Mg}$ alloy to evaluate the effect of introducing a rm anneal following HPT processing. This alloy had an initial annealed grain size of $\sim 400 \mu \mathrm{m}$ which was refined to $\sim 200 \mathrm{~nm}$ with a high fraction of high-angle grain boundaries through processing by HPT at room temperature.

[2] The introduction of short-term annealing for 10 minutes following the HPT processing led to a small reduction in strength but a significant increase in ductility. The optimum postHPT annealing condition for Al-1\% Mg alloy was identified as an anneal for 10 minutes at a temperature of $423 \mathrm{~K}$.

[3] It is suggested that HPT processing plus post-HPT annealing provides an alternative processing route for developing micro-forming materials.

This work was supported by the European Research Council under ERC Grant Agreement No. 267464SPDMETALS.

\section{References}

[1] Y. Qin, A. Brockett, Y. Ma, A. Razali, J. Zhao, C. Harrison, W. Pan, X. Dai, D. Loziak, Int. J. Adv. Manuf. Technol. 47, 821 (2010)

[2] Y. Qin, J. Mater. Proc. Technol. 177, 8 (2006)

[3] M. Geiger, M. Kleiner, R. Eckstein, N. Tiesler, U. Engel, Microforming, Ann. CIRP 50(2), 445 (2001)

[4] U. Engel, R. Eckstein, J. Mater. Proc. Technol. 125-126, 25 (2002)

[5] N.K. Tran, Y.C. Lam, C.Y. Yue, M.J. Tan, Int. Scho. Sci. Res. Innov. 6(5), 819 (2012)

[6] Y. Saotome, A. Inoue, Proceedings IEEE Micro Electro Mechanical Systems. An Investigation of Micro Structures, Sensors, Actuators, Machines and Robotic Systems (Cat. No.94CH3404-1) 343 (1994)

[7] R.Z. Valiev, R.K. Islamgaliev, I.V. Alexandrov, Prog. Mater. Sci. 45, 103 (2000)

[8] R.Z. Valiev, T.G. Langdon, Prog. Mater. Sci. 51, 881 (2006)

[9] A.P. Zhilyaev, T.G. Langdon, Prog. Mater. Sci. 53, 893 (2008)

[10] J. Wang, Z. Horita, M. Furukawa, M. Nemoto, N.K. Tsenev, R.Z. Valiev, Y. Ma, T.G. Langdon, J. Mater. Res. 8, 2810 (1993)

[11] Z. Horita, D.J. Smith, M. Furukawa, M. Nemoto, R.Z. Valiev, T.G. Langdon, J. Mater. Res. 11, $1880(1996)$

[12] Z. Horita, D.J. Smith, M. Nemoto, R.Z. Valiev, T.G. Langdon, J. Mater. Res. 13, 446 (1998)

[13] R. Valiev, Nature 419, 887 (2002) 


\section{ICNFT 2015}

[14] R. Valiev, Nature Mater 3, 511 (2004)

[15] S.G. Kang, Y.S. Na, K.Y. Park, J.E. Jeon, S.C. Son, J.H. Lee, Mater. Sci. Eng. A 449-451, 338 (2007)

[16] W.J. Kim, S.J. Yoo, H.K. Kim, Scrip. Mater. 59, 599 (2008)

[17] J. Xu, X. Zhu, L. Shi, D. Shan, B. Guo, T.G. Langdon, Adv. Eng. Mater. (in press) doi: 10.1002/adem.201400448

[18] J. Xu, C. Wang, D. Shan, B. Guo, T.G. Langdon, Manuf. Rev. 2, 1 (2015)

[19] O. Andreau, J. Gubicza, N.X. Zhang, Y. Huang, P. Jenei, T.G. Langdon, Mater. Sci. Eng. A 615, 231 (2014)

[20] R.B. Figueiredo, P.H.R. Pereira, M.T.P. Aguilar, P.R. Cetlin, T.G. Langdon, Acta Mater. 60, 3190 (2012)

[21] A. Loucif, R.B. Figueiredo, M. Kawasaki, T. Baudin, F. Brisset, R. Chemam, T.G. Langdon, J. Mater. Sci. 47, 7815 (2012). 